\title{
SOME URGENT AND FUNDAMENTAL ISSUES TO COMPLETE LAWS AND POLICIES ON ETHNIC MINORITIES IN MOUNTAINOUS REGIONS OF VIETNAM
}

\author{
Dr. Nguyen Quoc Suu \\ Associate Professor, Hanoi University of Internal Affairs, Vietnam \\ Dr. Ngọ Văn Nhân \\ Hanoi Law University, Vietnam
}

\begin{abstract}
In Vietnam, ethnic minority issues are considered to be a fundamental, urgent, long-term and strategic. These are the duties of the Party, the people, the army, and the whole political system. Over the past years, the Party and the State of Vietnam have passed many guidelines, policies and laws related to the issues of ethnic minorities and mountainous areas. However, in the process of organizing and implementing, there are still many difficulties and obstacles. In this study, the author uses the method of sociological investigation and expert interviews to initially identify the fundamental and urgent issues in the legal policy formulation on ethnic minorities and mountainous areas in Vietnam now.
\end{abstract}

Key words: fundamental, urgent, policy building, law, ethnic minorities, mountainous areas, Vietnam.

Cite this Article: Nguyen Quoc Suu and Ngọ Van Nhan, Some Urgent and Fundamental Issues to Complete Laws and Policies on Ethnic Minorities in Mountainous Regions of Vietnam, International Journal of Management, 11(12), 2020, pp 20-29.

http://iaeme.com/Home/issue/IJM?Volume=11\&Issue $=12$

\section{INTRODUCTION}

According to the 2019 Population and Housing Census, Vietnam has 53 ethnic minorities, accounting for $14.7 \%$ of the country's population with 14.1 million people, of which 6 ethnic groups have a population of over 1 million people (Tay, Thai, Muong, Khmer, Nung and Mong), 5 ethnic groups with the population under 1,000 people ( $\mathrm{Si} \mathrm{La}, \mathrm{Pu} \mathrm{Peo}$, Ro Mam, Brau, O Du). They mainly live in the Northwest, Central Highlands, Southwestern and Central Coast. These are considered to be important strategic positions of the country in 
socio-economic development strategies and security and defense assurance by the Party and the State. The ethnic minorities and mountainous regions account for about a quarter of the land area with 5,468 communes, accounting for $49.0 \%$ of the total number of communes throughout the country. They are mainly of rural areas $(87.3 \%)$ under the command of $503 / 713$ districts, towns and cities in 54/63 centrally-controlled provinces and municipalities (Committee for Ethnic Minorities, 2019).

Vietnamese ethnic groups form a unified community with their diversity of values, cultural nuances, customs, traditions, languages ... The mixing, uneven distribution, living mainly in mountainous, remote and isolated areas with uneven development level are the significant concerns of the ethnic structure in our country. Through thousands of years of history of building and defending the country, Vietnamese people have always been shoulder by shoulder, unified in the fight against foreign invaders, against natural disasters and joining hands to build the country of Vietnam.

In any historical period, there have been issues of economy, politics, culture, society, security, national defense, law...related to ethnic minorities and mountainous areas that need researching and solving both theoretically and practically, including the problem of building legal policies. It is necessary to identify fundamental and urgent issues so as to make policies and laws on ethnic minorities and mountainous areas effective.

\section{CONCEPTS OF FUNDAMENTAL AND URGENT ISSUES IN THE LEGAL FORMULATION OF ETHNIC MINORITIES AND MOUNTAINOUS AREAS IN VIETNAM CURRENTLY}

There are two main tendencies in dealing with the relationship between "fundamental problems" and "urgent problems" at present. The first one is the combination of the two and does not specify what is fundamental and what is urgent. The second considers "fundamental issues" and "urgent issues" as two separate groups; it differentiates fundamental ones from urgent ones and vice versa. The author believes that the relationship between the fundamental and urgent issues should be viewed in a "clearer" way, at the same time in a "more flexible" way than the two above mentioned views. On the one hand, there are important differences between the "urgent" and "fundamental" issues, especially in the scope of the impact and the policy requirements to cope with the emerging problems. Therefore, the distinctions between the fundamental issues and the urgent issues should be identifies in order to make it possible to determine the appropriate legal and policy response manners.

The following questions should be answered:

Firstly, what is a fundamental issue? This is a question whose answers that have not completely been agreed upon by Vietnamese researchers. In our opinion, a matter that is considered fundamental for a community in a country should satisfy two conditions: (i) It is the one that has been existed for a long time, with stable and core features rooted in the history of a community or of a nation; (ii) These must be the ones that have particularly great and intensive impacts on the economic, political, cultural and social life of the community or nation in terms of the overall historical length of the country instead of emerging at several specific times. Since the fundamental issues are essential, stable, and permanent by nature, it is not possible to deal with them with temporary and short-term solutions, but there should be a strategic vision, worthy decisions and long-term, fundamental and thorough solutions.

Second, what is an urgent issue? Besides the concept of a fundamental issue, researchers in Vietnam and the world today still widely use the concept of urgent problems. Like fundamental ones, urgent issues also have a great impact on the political, economic, cultural and social life of a community or a nation. However, unlike the fundamental problems, urgent 
matters are not necessarily long-term and stable ones, but rather things, events and phenomena that newly arise in practice. Simultaneously, these issues are not the ones with the greatest impact in the overall history of the country, but at the present moment or in a short period of time. While the fundamental problems require to be handled with long-term, stable and thorough solutions, the urgent problems need solving immediately with prioritizing resources in the shortest time.

In our opinion, in the current development of legislation on ethnic minorities and mountainous areas, the relationship between the "fundamental issues" and "urgent issues" is in the form of "two in one, one but two "; "Two in one" because both the "fundamental matters" and the "urgent matters" are the most important and necessary ones that must be addressed by the Party and the State, the Law at the national level to ensure that no one of the ethnic and mountainous communities is "left behind". "One but two" means: those most important and necessary issues that have existed for a long time, stable and fundamental in the history of ethnic minority and mountainous areas; what need resolving gradually, in the medium or long term, are the "fundamental problems"; but for those of the most important, necessary but emerging at the forefront, urgently needed solving immediately in a short term especially in the present time, those are "urgent problems".

Thus, the "fundamental issues" and "urgent issues" in the current formulation of legislation on ethnic minorities and mountainous areas mingle with each other. The "fundamental issues" when emerging at the top, needed solving in a short term, become "urgent issues"; while the "urgent issues" which have been handled and resolved quite satisfactorily, relatively thoroughly, but still need to be further strengthened and maintained in a stable and sustainable way in the long term are the "fundamentals".

\section{THE FINDINGS}

By July 2019, in institutionalizing the Party's guidelines, the National Assembly has issued 108 laws and over 30 resolutions with policies related to ethnic minorities, mountainous areas and extremely difficult areas, including civil and political fields; national defense and security, ensuring social order and safety; economics, labor force and employment; cultural information; education and training, human resource development, improving people's knowledge; healthcare system, people's healthcare; environmental protection; personnel issue, building the political system (Hoang Van Tu et al., 2019). The ethnic policy system built by the Government, ministries and sectors has 118 documents, of which 54 ethnic minority schemes and policies directly support socio-economic development in ethnic minority and mountainous areas (Phan Van Hung, 2019). Since the Doi moi (Renovation), the implementation of the national policies of the Party and State has made great achievements in all fields of social life. Equal rights among ethnic groups have been fully carried out in all fields of society. Solidarity among ethnic groups continues to be consolidated. The economy of ethnic minority and mountainous areas has made remarkable progress, the annual economic growth rate is high ( $8 \%$ per annum on average). The multi-sector economy has been initially formed and developed, shifting towards commodity production. Many specialized crop cultivation regions have been formed and producing large quantities of goods. Infrastructure in ethnic minority and mountainous areas has been remarkably improved; greatly contributing to socio-economic development and improving the lives of ethnic minorities. Poverty alleviation has achieved great results. The living standards of ethnic minorities have been significantly improved.

However, ethnic minority areas in Vietnam currently have the following major difficulties and challenges: Most of the rural areas where ethnic minorities live in concentration have not yet been planned; they are far from district and provincial centers. Provinces with a large 
ethnic minority population are among the poor and poorest in the country, far from regional developmental hubs; natural resources in mountainous areas are running out rapidly. The deforestation is increasingly serious, the biodiversity of many of the most precious forest areas of our country is disappearing; the surface and ground water sources are exhausting, and water sources are in danger of being heavily polluted. Mineral resources in many places have been uncontrolledly exploited. There are still many underdeveloped economic regions, not commensurate with their potentials; the economic and labor structures have been shifted slowly. Production practices, tools are primitive, out of date, and labor productivity is very low. The quality of education and the quality of human resources are limited. The rate of trained labor force in ethnic minorities is very low, ranging from $5 \%$ to less than $10 \%$, notably in some groups only 1-2\% (Tran Quoc Cuong, 2020). The cultural identities of many ethnic groups are in danger of fading. Backward practices and superstitions still exist in some remote areas. Although access to health care services has been improved, the quality remains low. The quality of the population, physically, intellectually and mentally, of some people in the communities and villages in remote and mountainous areas is very poor compared to the average development indicators of localities in each criterion. Due to many objective and subjective reasons, the land for residence, land for production, and land for the community of ethnic minorities in many places have been relatively or absolutely narrowed down. The quantity and quality of ethnic minority cadres in all sectors and levels are very limited, especially at the central level, in economic management sectors, and staff holding management positions from department level or higher. At the same time, the cadres at the grassroots level in many remote, difficult and extremely difficult areas still show many limitations in qualification, background knowledge, professional knowledge, competence, and skills to perform the duties. The religions and beliefs in ethnic minority areas are very diverse and there are many extraordinary places; In some places, religion has been used by bad people to gather forces, inciting the residents to undermine national unity, oppose the Party, fight the regime, demand separatism. Domestic and foreign reactionary organizations take advantage of complicated and difficulties in ethnic minority areas to incite and gather forces to cause instability in political security and social order (National Assembly, 2019). So what are the fundamental and urgent issues in making legal policies for ethnic minority and mountainous areas in Vietnam today?

In order to identify the fundamental and urgent issues in policy and law formulation on ethnic minorities and mountainous areas, we have delivered the question: "In your opinion, which of the following issues are urgent in the building the legislation on ethnic minorities and mountainous areas in our country?" to 650 officials, central civil servants and National Assembly Representatives; the number of votes collected was 600 . The question allows the respondents to choose multiple answers with the convention that all 06 given problems are the fundamental problems and 03 voted the most are fundamentals in law-making about ethnic minorities and mountainous areas. Survey results are shown in the following table: 
Table 1 Identifying the fundamental and urgent issues in the current policy and legal formulation of ethnic minorities and mountainous areas in our country

\begin{tabular}{|c|c|c|c|c|}
\hline $\begin{array}{c}\text { Type } \\
\text { of } \\
\text { varieb } \\
\text { le }\end{array}$ & No. & $\begin{array}{l}\text { What are the urgent issues in legislation formulation on ethnic } \\
\text { minorities and mountainous areas? }\end{array}$ & No. of vote & $\begin{array}{l}\text { No. of voted rate } \\
\text { selected by issue }\end{array}$ \\
\hline \multirow{7}{*}{$\begin{array}{l}\text { Valid } \\
\text { variab } \\
\text { le }\end{array}$} & 1 & $\begin{array}{l}\text { Institutionalization of policies and guidelines of the Communist } \\
\text { Party of Vietnam on ethnic minorities and mountainous areas into } \\
\text { policies and laws }\end{array}$ & 477 & 79,5 \\
\hline & 2 & $\begin{array}{l}\text { Realization of the provisions of the Constitution into policies and } \\
\text { laws for ethnic minorities and mountainous areas }\end{array}$ & 498 & 83,0 \\
\hline & 3 & $\begin{array}{l}\text { Integration and compatibility issues between Vietnamese laws and } \\
\text { international and regional laws in the policies for ethnic minority } \\
\text { and mountainous areas }\end{array}$ & 445 & 74,2 \\
\hline & 4 & $\begin{array}{l}\text { Promoting legislative activities towards synchronization and } \\
\text { upgrading of legal validity of legal documents on ethnic } \\
\text { minorities and mountainous areas }\end{array}$ & 566 & 94,3 \\
\hline & 5 & $\begin{array}{l}\text { Ensuring democracy in policy and law making activities related } \\
\text { to ethnic minorities and mountainous areas }\end{array}$ & 556 & 92,6 \\
\hline & 6 & $\begin{array}{l}\text { Assessment of impacts of policies and laws on mountainous } \\
\text { ethnic minorities on ethnic minorities and mountainous }\end{array}$ & 386 & 64,3 \\
\hline & 7 & Other issues & 0 & 0,00 \\
\hline & & Total & 600 & 100,00 \\
\hline
\end{tabular}

The data in Table 1 shows that all 06 issues were chosen by the majority of officials and public servants participating in the survey; in which, the issue of "promoting legislative activities towards synchronization and upgrading of legal validity of legal documents on ethnic minorities and mountainous areas" accounts for the highest percentage of $94.3 \%$ with 566/600 people chosen; the up-runner was the issue of "ensuring democracy in policy and law making activities related to ethnic minorities and mountainous people", chosen by 556/600 people, accounting for 92.6\%; the issue of "realizing the provisions of the Constitution into policies and laws for ethnic minorities and mountainous areas" was chosen by $498 / 600$ people, accounting for $83.0 \%$. The three issues mentioned above have become the urgent issues in the current development of legislation on ethnic minorities and mountainous areas in our country.

\section{DISCUSSION}

\subsection{The current fundamental issues in policy and law development on ethnic minorities and mountainous areas in Vietnam}

Firstly, the issue of institutionalizing the guidelines and directions of the Communist Party of Vietnam on ethnic minorities and mountainous areas into policies and laws. The issue of law building can be generally understood as "an extremely important and complex operation process, consisting of many consecutive activities, closely related to each other, carried out by many organizations, individuals with different positions, roles, functions and powers in order to transform the wills of the State and the Vietnamese people into legal provisions based on certain principles and shown under certain legal forms, mostly legal documents" (Nguyen Minh Doan, 2011). The development of a specialized law and regulations on supporting the development of ethnic minorities and mountainous regions is institutionalizing the policies of the Communist Party of Vietnam on the ethnic policy as stated in Party Documents, such as the Resolution of the 7th Congress, the 12th Party Central Committee on Ethnic Affairs, National Construction Platform in the Transitional Period to Socialism (added and developed in 2011), other documents of the Party related to the policies of ethnic groups and mountainous areas in the Doi moi (Renovation) period. At the 12th National Congress, our 
Party reaffirmed: "Continuing to improve mechanisms and policies, ensuring equality, respect, solidarity, and harmonious settlement of relations among ethnic groups, helping each other to develop, making remarkable changes in economic, cultural and social development in the areas with a large number of ethnic minorities, especially in the Northwest, Central Highlands, South West, and Western Central Coast" (Communist Party of Vietnam, 2019).

Secondly, the issue of realizing the provisions of the Constitution into policies and laws for ethnic minorities and mountainous areas. The Constitutions of our country from 1946 to present, especially the 2013 Constitution, all solemnly reserved articles and provisions on ethnic minorities and mountainous areas, especially political, economic, cultural, civil rights. More importantly, the State should realize those provisions of the Constitution into policies and laws for ethnic minorities and mountainous areas so that they can fully enjoy their rights and fulfill their obligations to the utmost on the process of building and developing the country of Vietnam.

Thirdly, the issue of integration and compatibility between Vietnamese law with international and regional laws in the policies for ethnic minority and mountainous areas. Currently, Vietnam has acceded to / ratified a number of international treaties such as the 1966 Convention on Civil and Political Rights; The 1966 Convention on economic, cultural and social rights, the 1979 Convention on the Elimination of All Forms of Discrimination against Women, International treaties related to ethnic issues within the framework of ASEAN countries. In the context of ethnic and religious conflicts in the world, internalizing the laws and the strict implementation of international treaties related to the ethnic domain to which Vietnam is a member and the effective implementation of international recommendations on ethnic groups that have been accepted by the Government of Vietnam (after the Second Periodic Universal Review on Human Rights) is of great importance. It reaffirms the goodwill and special attention of our State in the implementation of international laws on human rights assurance, civil rights and dialogues on human rights of Vietnam. However, as analyzed, the legal system on this issue is mostly of a general principle as stipulated in the 2013 Constitution, lacking legal documents to correct the guarantee for equal right and development of ethnic minorities living in the territory of Vietnam.

The researches into the international experiences show that some countries with many ethnic minorities have issued laws on ethnic groups, which stipulate support for ethnic minorities, such as: Law on Ethnic Minorities of the Czech Republic 2001; Croatia's Ethnic Minority Rights Act 2002; Law on Ethnic Minorities of Ukraine 1992; Law on Poland's national and ethnic minorities and regional language; Hungarian Law on Ethnic and Minority Rights 1993; Law No. 8371 which recognizes, protects and promotes the rights of cultural minority / ethnic communities of the Philippines in 1997, establishing the National Committee on Ethnic Minorities, establishing mechanisms in implementing and using budget. Thanks to these, the situation of ethnic minorities in these countries is basically stable, they unite and support each other for development. Vietnam can refer to the experiences of these countries to formulate and promulgate the Law on Development of Ethnic Minorities \& Mountainous Areas.

Fourth, the issue of promoting legislative activities towards synchronization and upgrading of legal validity of legal documents on ethnic minorities and mountainous areas. In fact, guidelines, directions, policies and laws on ethnic minorities and mountainous areas have been paid special attention by the Party and State over the past years, but these have not been drastically and actively implemented with the direction of synchronizing and upgrading the legal validity of legal documents on ethnic minorities and mountainous areas. According to the verification agencies, policies and laws related to ethnic minorities and mountainous people are scattered, fragmented, redundant, insufficient, overlapping in content, areas and 
beneficiaries. These policies and laws mainly exist in the Government decrees, Prime Minister's decisions. In one area, the level of support in some policies is different for the same subjects, making it difficult to implement and assess the effectiveness. Policies often support, provide necessities for free, solve the temporary situations, do not focus on investment and development to exploit regional strengths, and there are no policies to encourage ethnic minorities to get out of poverty sustainably. The policy objectives are ambitious, but the time and resources are limited and often need to be extended. Some policies have been issued with short-term effect, not long-term and consistent forecasts.

Fifth, the issue of ensuring democracy in policy and law formulation activities related to ethnic minorities and mountainous areas. With the features of divided topography, remote geography, cultural differences, economic difficulties, weak infrastructure and technical materials, difficult access to information, ensuring the democracy in ethnic minority policies and law formulation activities face many limitations and shortcomings. This is also the main problem that has existed for a long time. In that context, the participation of ethnic minorities and mountainous people in the development of policies and laws related to their own life is the only way for these policies and laws to come into practice, positively impacting the lives of the people. Responsibilities of the authority in this case need to be strengthened and have a deep sympathy with the people in the places where policies and laws may affect.

Sixth, the issue of assessment the impact of mountainous ethnic minority policies and laws on ethnic minorities and mountainous areas. "The directly affected objects by the legal document are the agencies, organizations or individuals whose rights, obligations and responsibilities are directly affected by the application of such document after being issued" (National Assembly, 2015). Impact assessment has a significant meaning, strongly affects the effectiveness, efficiency and vitality of policies and laws related to ethnic minorities and mountainous areas when they come into practice in social life. How laws have met the demand considering the interests of subjects directly affected by policies is decisive in ensuring the effectiveness and efficiency of the proposed policies and laws. In many cases, because there is no evaluation or there is incorrect, incomplete or inaccurate assessment of the impact of a particular policy, of a legal document, or even of a particular legal law on the interests of the directly affected subject, the newly issued legal law consequently faces strong objections from the affected objects. This is also a fundamental issue, requiring concerned agencies to pay special attention to when formulating policies and laws on ethnic minorities and mountainous areas.

\subsection{Urgent issues in the law formulation on ethnic minorities and mountainous areas in Vietnam today}

(i) Realization of the provisions of the Constitution into policies and laws for ethnic minorities and mountainous areas. This urgent issue should be implemented in association with the development and completion of legislation on ethnic minorities and mountainous areas with the following specific requirements:

Ensuring that the rights of ethnic minority people should be institutionalized by law, respected as well as protected by law and have practical values; ensuring the consistency between general laws and specific regulations. Institutionalization of specific rights should be based on the country's specific socio-economic conditions and circumstances, in each appropriate period.

Associated with the synchronous and comprehensive implementation of programs and policies for infrastructure development, socio-economic development, poverty reduction, improvement of social services and preservation of cultural values in ethnic minority areas, mountainous areas to ensure economic rights for everyone, implementation social justice and 
gradually narrowing the gap between the rich and the poor among regions and ethnic minorities; There should be special policies to make a comprehensive change in the political economic - cultural life of ethnic minorities in a fundamental way according to development goals.

- Developing a regime of responsibility for implementing duties of civil servants, especially cadres working in ethnic minority areas, to ensure that each person can bring into full of their personal capacity; At the same time, specifying their responsibilities in the process of carrying out duties, minimizing the risk of infringing upon citizens' rights, human rights towards ethnic minorities who are the subjects of limited legal understanding level, easily being hurt and less likely to protect themselves.

- Building internal capacity is considered a priority for ethnic minorities to implement and integrate into national development policies, self-select and protect fundamental values and interests of individuals and communities within the framework of the state law system in general, doing well in education, improve the quality of human resources, increase awareness and disseminate legal education to all ethnic minorities.

(ii) The issue of promoting legislative activities towards synchronization and upgrading of legal validity of legal documents on ethnic minorities and mountainous areas. The most practical solution, making it possible to overcome the situation of policies and laws related to ethnic minorities and mountainous areas are still scattered, fragmented, redundant, lacking and overlapping in content and areas and beneficiaries. And these policies and laws mainly are mainly in the form of Decrees of the Government, Decisions of the Prime Minister is by building and promulgating the Law on Support for Development of Ethnic Minorities and Mountainous Areas. In addition, attention should be paid to the following aspects:

- Renovate regulations in the legal system on election and candidacy to strengthen the political power of the people, including enhancing the propaganda and awareness of political rights for ethnic minorities together with specific measures to create conditions for people to exercise their basic rights.

- Review the system of relevant legal documents to supplement the necessary requirements to increase the people's participation in local management activities, state management, and self - community management activities.

- Expand appropriate forms of democracy in the life of ethnic communities so that they can participate more effectively in management processes.

- For civil rights, it is necessary to increase information and disseminate legal education to the people in order to improve understanding of rights and responsibilities in the general regulation system. In addition, policies related to the principle of residence rights of some groups of free migrants also need supplementing and adjusting, adopting good practices in family marriage, gender equality rights.

- Continue to build the staff of ethnic minority cadres in order to increase their participation in the central state apparatus and local authorities at all levels. Concerning and doing well in planning the resources of ethnic minority staff to have policies on training, retraining and using appropriately, forming a large number of ethnic minority cadres being skillful in profession, being able to meet the requirements of socio-economic development of localities.

- Some other policies need to be added such as: planning, training and appointing ethnic minority cadres in the state apparatus system; building a contingent of ethnic intellectuals and policies for the typical people of ethnic minorities (not merely typical people at the grassroots level as the current policy goals); specifying more staff 
policies for some ethnic minority and mountainous areas to meet practical requirements in the new period.

- In the fields of education, human resource development, people's knowledge improvement, training and training resource fostering, it is necessary to amend a number of educational policies related to the implementation of the recruitment policy in training including training occupations, training subjects; modifying the civil servant and public employee recruitment policies to give priority to ethnic minority children, in line with population structure characteristics.

(iii) The issue of ensuring democracy in policy and law formulation activities related to ethnic minorities and mountainous areas. The general principle is that, in addition to the participation of relevant agencies in the policy-making process, in accordance with the Law on Promulgation of Legal Documents 2015, it is essential to ensure democracy in this approach: In the process of formulating policies and laws on ethnic minorities and mountainous areas, it is essential to ensure the participation of ethnic minorities and mountainous people in this activity, because those policies and laws closely and directly affect them, and their own daily life and work. Ensuring democracy is also the only way for these policies and laws to come into practice, positively impacting the lives of ethnic minorities and mountainous people.

\section{CONCLUSION}

On the basis of defining the conceptual content of "fundamental and urgent issues in lawmaking in ethnic minority and mountainous areas" and identifying the main content of fundamental and urgent issues in formulating Laws in ethnic minority and mountainous areas of our country base on the results of sociological surveys, this article focuses on assessing fundamental and urgent issues in policies and laws on development, investment, land, forest protection, education and training, health care, social security, new rural construction, on national defense and security, on population, conservation and promotion of cultural values, heritages and the implementation of grassroots democracy in ethnic minority and mountainous areas.

\section{REFERENCES}

[1] Tran Quoc Cuong, 2020, The formulation and implementation of Laws on ethnic minorities and mountainous areas in the Central Highlands, https://noichinh.vn/nghien-cuu-traodoi/202001/cong-tac-xay-dung-thuc-thi-phap-luat-ve-dan-toc-thieu-so-mien-nui-tai-taynguyen-307497/

[2] Communist Party of Vietnam, 2016, Documents of the 12th National Congress, Publishing House, National Politics - Truth, Hanoi, 2016, p. 164.

[3] Nguyen Minh Doan, 2011, Building and perfecting the Vietnamese legal system in the context of building a rule of law socialist state, Publishing House. National politics, Hanoi, 2011, p. 8.

[4] Phan Van Hung, Deputy Minister, Vice Chairman of the Committee for Ethnic Minorities, 2019: "Some issues in practice of current ethnic minority policies need a decisive role of the National Assembly", Hanoi.

[5] National Assembly, 2015, Law on Promulgation of Legal Documents 2015, Hanoi, Clause 2 Article 3.

[6] National Assembly, 2019, Project "Institutionalizing the Party's ethnic guidelines and lines, implementing Clause 5, Article 70, the 2013 Constitution of the National Assembly decides the ethnic minority policies of the State", Hanoi July 25, 2019. 
Some Urgent and Fundamental Issues to Complete Laws and Policies on Ethnic Minorities in Mountainous Regions of Vietnam

[7] Hoang Van Tu, Nguyen Cao Thinh, Hoang Thi Huong, 2019 "The Current Situation of the National Assembly's Decisions on Current Ethnic Policies and Some Recommendations", Hanoi.

[8] Ethnicity Committee, 2019, Press release: Survey results of information collection on the socio-economic situation of 53 ethnic minorities in 2019, http://www.cema.gov.vn/thongbao/thong-cao-bao-chi-ket-qua-dieu-tra-thu-thap-thong-tin-ve-thuc-trang-kt-xh-cua-53-dttsnam-2019.htm 